\title{
Article
}

\section{The changing pattern of domestic cannabis cultivation in the UK and its impact on the cannabis market}

\author{
Kirby, Stuart and Peal, Katie \\ Available at http://clok.uclan.ac.uk/12376/ \\ Kirby, Stuart ORCID: 0000-0002-3049-1248 and Peal, Katie (2015) The \\ changing pattern of domestic cannabis cultivation in the UK and its impact on \\ the cannabis market. Journal of Drug Issues, 45 (3). pp. 279-292. ISSN 0022 - \\ 0426
}

It is advisable to refer to the publisher's version if you intend to cite from the work. http://dx.doi.org/10.1177/0022042615580990

For more information about UCLan's research in this area go to http://www.uclan.ac.uk/researchgroups/ and search for <name of research Group>.

For information about Research generally at UCLan please go to http://www.uclan.ac.uk/research/

All outputs in CLoK are protected by Intellectual Property Rights law, including Copyright law. Copyright, IPR and Moral Rights for the works on this site are retained by the individual authors and/or other copyright owners. Terms and conditions for use of this material are defined in the policies page.

\section{CLoK}

Central Lancashire online Knowledge www.clok.uclan.ac.uk

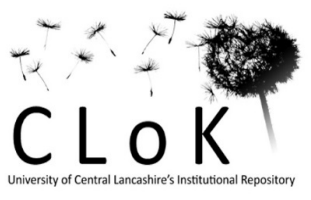




\title{
THE CHANGING PATTERN OF DOMESTIC CANNABIS CULTIVATION IN THE UK AND ITS IMPACT ON THE CANNABIS MARKET
}

Stuart Kirby, Lancaster University Law School, Lancaster LA1 4YT, England. Email: s.kirby@lancaster.ac.uk

Katie Peal, Lancaster University Law School, Lancaster LA1 4YT, England.

\begin{abstract}
With improvements in both technology and information cannabis is being increasingly grown indoors for domestic use, rather than being imported. This study examines 50 cannabis farms detected by an English police force, and examines the characteristics of the 61 suspects associated with them. The study highlights a UK pattern in domestic cultivation, that is moving away from large scale commercial cultivation, at times co-ordinated by South East Asian organised crime groups, to increased cultivation within residential premises by British citizens. Offenders range from those who have no prior criminal history to those who are serious and persistent offenders. The ramifications for law enforcement agencies and policy formers are discussed.
\end{abstract}

\section{INTRODUCTION}

Cannabis is ubiquitous, used by a diverse range of societies and cultures, being cited as the drug young people are most likely to encounter (Silverstone, 2011). Indeed some argue the normalisation 
of cannabis, especially among young people, has increased demand (Fountain and Korf, 2007); with policy solutions ranging between legalisation (or decriminalisation), and prohibition (Hall, 2009). Nevertheless, whilst the substance remains illegal across most locations, and demand remains high, the supply process remains a fertile ground for criminal entrepreneurs. These individuals adapt their methods to seize opportunities and navigate around obstructions (Ekblom, 2003; Kirby, 2013), with the increasing shift from importation to domestic cultivation the most recent development (Potter, 2008). In this rapidly changing environment it is vital to monitor trends to enable policy makers and criminal justice agencies devise and implement the most appropriate interventions. This study provides empirical data from 50 'cannabis farms’ identified by an English city police force; it examines the level of cannabis seizures, the premises and people involved, and the ramifications this has for policy makers. The first stage of this study will provide the context behind the proliferation of domestic cannabis cultivation.

\section{LITERATURE REVIEW}

\section{THE PROLIFERATION OF 'HOME GROWN' CANNABIS CULTIVATION}

To understand the evolution of domestic cannabis cultivation it is important to recognise that growers require some level of knowledge and specialist equipment. Optimum temperatures and light are needed to grow the plant and this, coupled with the risk of detection and interference by human and animal behaviour, generates complications when grown outdoors in countries such as the United Kingdom (IDMU, 2013). Further, cannabis can be produced and supplied in different forms with different varieties or strains having different levels of psychoactive properties. Dense blocks sourced from the secretion of the plants' flowers, commonly known as hashish is offered alongside herbal cannabis, known as grass/marijuana/ ganja, which is produced by harvesting dried flower stems, leaves and top shoots (Jenkins, 2006). Historically these complexities generally meant specialists would more often produce and import the drug on an organised scale. This generates higher prices as actors within the supply chain (from wholesaler, to middle market, to retailer) set their tariff to cover the costs required for transportation, security, and profit. 
Routine Activity theory (Felson, 2002), contends that crime is generated through the opportunities that emerge from the rhythms of everyday life. The theory argues that for a crime to be committed a motivated offender must come together, at the same time and place as a suitable target, in the absence of a capable guardian. In essence it argues criminal entrepreneurs adapt their illegal behaviour according to the external conditions and opportunities of the time; just as consumers may also change behaviour to obtain better quality or lower priced goods. These principles can be identified during the latter part of the $20^{\text {th }}$ Century when a number of drivers for change emerged. First the risks associated with cannabis were increased as many countries hardened their stance on the drug. This resulted in more vigorous eradication of outdoor crops, pursuit of offenders, and the seizure of illegal imports (Gettman, 2006). Nevertheless these risks were balanced with new opportunities as improvements in technology emerged. Indoor growing became possible with the technological advancements in hydroponics and lighting (Potter, 2008; Potter et al., 2011). From the 1980s these advancements were concentrated in the Netherlands as production of hemp seeds remained legal, and the area became known as “an ideal 'incubation country' for further developing both the genetics and production techniques” (Decorte 2010:272; Jansen, 2002). A further facilitating factor was that late modernity signalled the increased mobility of people, services and information, which assisted the spread of specialist knowledge to an increasingly globalised world (North America, Australasia and Europe) (Decorte, 2010). Information for the budding cannabis cultivator became readily accessible through the internet, magazines and specialist retailers (known as grow shops), selling indoor cultivation equipment (Potter, 2010; Decorte, 2010).

This evolution, from importation to indoor domestic cultivation, became an "adaptive and innovative strategy" (Bouchard, 2007:222). The method became more operationally and financially viable as it reduced the number of people that needed to be involved, thereby reducing the risk of detection as well as lowering the handling and transportation costs (Jansen, 2002; Potter et al. 2011). The impact was soon evident. Daly (2007:8) reported a case study in Surrey (UK), where, "In their six months of occupation the skunk [marijuana] farmers had earned an estimated £100,000 from two crops, caused a 
further $£ 10,000$ in damage, left a £6,000 electricity bill and wiped $£ 20,000$ from the value of the house.” This economic reward to the grower continued to change the demographics of domestic markets, with local dealers soon highlighting imports were falling as local cultivation thrived. This made the availability of resin (which is more likely to be imported), less accessible compared to herbal cannabis (Potter et al. 2011).

Changing policy, police practice, and increased media publicity mean that figures derived from police sources should be treated with caution. Notwithstanding this concern the pace of change concerning domestic cannabis cultivation was considered significant. Kirby \& Penna (2010) examining the records of an English county police force discovered whilst only five cannabis factories were discovered in 2007, 42 were discovered a year later. These operations were quick and inexpensive to set up, often found in commercial rented accommodation, and predominantly operated by South East Asian (generally Vietnamese) nationals. This trend was found across the UK with official statistics showing a total of 3,032 commercial cannabis farms identified in 2007/08, which rose by over $150 \%$ to 7,660 in 2010/11. This number was estimated to rise to 7865 in 2011/12 (ACPO, 2012: 10), meaning 21 farms would be discovered and dealt with in the UK each day. A survey of UK police seizures in 2008, showed that 81\% comprised domestic herbal cannabis (ACPO, 2012), and in 2011 $65 \%$ of the total UK cannabis market was domestically produced (IDMU, 2011). Indeed the public are being told that half a million people are growing cannabis in the UK, which could be estimated as almost one on every street (Woodman, 2013). The most recent analysis, generated by the Serious Organised Crime Agency, argued cannabis in the UK was a £1billion per annum industry, with 270 tonnes needed each year to meet demand (NCA, 2014). Further, as commentators observe, "Cannabis cultivation is increasingly universal” (Potter et al. 2011:1), with research showing an increase in other countries. Wouters (2008) states 6000 cannabis cultivation sites are being dismantled each year in Belgium, whilst Akgul \& Sever (2014) reported Turkish law enforcement agencies destroyed over 20 million plants in 2012. Similarly Bouchard et al. (2009) reporting on research in Quebec, Canada argued over 50,000 people now work in cannabis cultivation, a rapid and substantial change from the small amount of importers previously involved. 


\section{THE GROWER}

As the method of supply evolves it is useful to examine the profile of growers. A number of typologies have differentiated different categories of domestic cannabis farmers, often highlighting those who grow for ideological means (more often for sole use) and those who grow commercially, although a cross over between the two are often reported (Potter 2010). Hough et al. (2003) defined UK growers as follows:

- The sole-use grower: cultivating cannabis for their personal use and use with friends

- The medical grower: individual and others use, purely for medical reasons

- The social grower: cultivation to ensure good quality and good value cannabis for themselves and friends

- The social/commercial grower: growing for themselves and friends but with an element of profit

- The commercial grower: growing to make money, with anyone as a possible customer. (Edited from Hough et al., 2003:ix).

Unsurprisingly the boundaries between these categories are not always well defined. For example the social/commercial grower (Hough et al., 2003) is someone who is described as earning large profits, but only selling to friends. Other commentators argue there is growing market fragmentation, with less reliance on a 'Mr Big' sole supplier (Potter, 2008; 2011). Ideological reasons, often associated with small crops (Hough et al., 2003), can include: political reasons; saving money; medical needs; and to guarantee the quality and purity of the commodity (Potter, 2008). Further, the pleasure involved with growing the drug (Weisheit, 1991), coupled with the ability to avoid 'real' drug dealers, organized crime, the black market, the risk of arrest and an association with Class A drugs also appear in the explanations provided (Hough et al., 2003). Conversely commercial growers are predominantly driven by profits, although there appear some exceptions. Weisheit (1992) describes three types of 
commercial growers in America: 'Hustlers' who enjoy the success of cultivation and its perks; 'Communal growers' who choose to cultivate as a lifestyle choice, rather than primarily for financial gain; and 'Pragmatists' who use cannabis cultivation as a source of income in difficult times. Wilkins et al. (2002:369) also linked cannabis cultivation to ‘economically depressed rural areas'. Hough et al.’s (2003) UK research unearthed that commercial growers grew the best crop to allow them to charge higher prices; these respondents were all observed to use hydroponic techniques and grew between two and ninety plants at a time (Hough et al., 2003). One respondent reported earning enough money (on average £2,500 a month), to leave his regular employment (Hough et al., 2003).

Nearly a decade after these studies the Association of Chief Police Officers in England and Wales (ACPO) has emphasized the relationship between organized crime and commercial growing, enhanced by the large profit margins and the low risk of sanction compared to other types of drug production and supply (ACPO, 2012). In fact others report Class A drug dealers (heroin, cocaine), are increasingly engaged in cannabis cultivation due to its high-profit status (Shute, 2013). ACPO (2012) has also noted an increase in burglaries, robberies and violence associated with cannabis farms. Further, South-East Asian organized crime groups, who previously ran two-thirds to three-quarters of all cannabis farms in the UK (Daly, 2007), appear to have lost their market share to the indigenous British population (ACPO, 2010). It is suggested although a large number of South-East Asian immigrants are still being arrested, these are now working as 'gardeners' in the farms (ACPO, 2010). The UK Police also report organized crime groups are creating new initiatives to reduce risk and increase profit; for example moving from large sites to smaller farms, stealing cannabis crops from others, and requiring others to grow on their behalf (ACPO, 2012).

\section{THE CRIMINAL JUSTICE RESPONSE}

The policing of cannabis has often been surrounded by ambiguous, controversial and changing policy interventions (see Akgul \& Sever, 2014). This is typified by the UK who first regulated cannabis in 
1924 under The Poisons Act, when little domestic use was present (Mills, 2003). The Misuse of Drugs Act 1971 followed and provided more comprehensive legislation to prohibit the importation, exportation, production, supply, possession and cultivation of cannabis (Potter, 2008:88). This was supplemented by the Drugs Trafficking Act 1994 which made the production of cannabis a trafficking offence (Potter, 2008). In January 2004 the British government downgraded cannabis from Class B to Class C status (ACPO, 2010), and this coincided with an increase in domestic cultivation. The response was two fold. In January 2009 the classification was returned to Class B, with the Home Secretary stating she wanted the UK to be "a high risk place for them [cannabis farms] to operate" (ACPO, 2010:2). Secondly, attempts were made to standardise the response to cannabis cultivation, with government advice stating "Cultivation of cannabis should be regarded as 'commercial' if: Twenty-five or more cannabis plants, at any stage of growth (germination), are being or have been grown OR there is evidence of a 'cannabis farm'” (ACPO, 2012:6). Although some academics would argue otherwise (see Potter 2010; 2011) official guidance further stated that those who are in possession of fewer than 10 plants are thought unlikely to be supplying others, whilst anything over 10 plants suggests excess amounts (ACPO, 2012).

It is reported cannabis farms within the UK are rarely identified by the public (Collison, 1995), with the policing of cannabis seen as "largely reactive and rarely proactive” (Potter, 2008:98). Discovery often occurs through: fires (Daly in 2007, reported the London Fire Brigade found 50 farms); neighbours reporting 'cannabis houses' being broken into (ACPO, 2010); or police officers detecting the smell during routine enquiries (Potter, 2008). Trying to prevent the continuation of cannabis cultivation in the UK has been portrayed as an impossible task with those detected soon replaced by others (Collison, 1995), and internationally there appears no evidence that domestic cannabis cultivation is decelerating (Wouters et al. 2007; Spapens et al. 2007). Although the identification of farms is becoming increasingly innovative as helicopters and hand-held devices identify heat sources, so offenders adapt, creating displays in front rooms to make them looked inhabited (Daly, 2007). The Netherlands approach is said to mirror the policy observed in many other countries, being described as “a hit and run practice, busting a maximum number of sites with maximum efficiency, but not 
weighing the potential impact on organised crime” (Decorte, 2010). A concerted effort in London between 2005-2007, resulted in 1,500 cannabis farms raided and dismantled, a three-fold increase compared with the previous two years (Daly, 2007). During the operation a Metropolitan Police Commander said it aimed to "send out a clear message that cannabis production is a serious offence and that offenders will be brought to justice” (CJP, 2006). However, as Kennedy (2008) shows, no matter what the Police say, deterrence value is limited when offenders know the real risk of detection is low. Also crackdowns can have unintended consequences as inferior and polluted products can invade the market, taking advantage of desperate and indiscriminate consumers (Daly, 2007). A possible alternative to targeting cannabis farms could be to target the apparatus used to grow cannabis (Potter, 2010). Although undoubtedly making it far more difficult to grow cannabis, especially to the quality necessary for high-profits (Potter, 2010), this would be difficult as the legal grow shops sell equipment for legitimate purposes. Currently a more liberal view to small levels of cultivation operates in The Netherlands and is explained as "grudging toleration” (May et al., 2002:13). Further, Uruguay and specific US states have recently legalized cannabis, suggesting that the public perception of harm has reduced dramatically (Travis, 2014). It is thought this trend will continue, facilitated by the tax revenue it generates.

In summary the domestic cultivation of cannabis remains a complex problem, constantly evolving in a changing environment. Decorte (2010) argues significant questions remain unanswered in this field, such as the prevalence and role of social-commercial cultivators, asking to what level the noncommercial cultivators currently exist. Further the Criminal Justice perspective is also underresearched in this area. It is to these areas that this research now turns.

\section{METHODOLOGY}

The study was conducted in a police district situated within a city police force in the North of England. The area covers 41 square miles, and comprises a number of towns that are resident to an 
urban and racially diverse population of approximately 226,600 people. After subjected to appropriate vetting procedures the researchers were given access to relevant information from police and local government systems.

A mixed method approach was used. Initially a quantitative approach examined cannabis farms dealt with by the Police between 2011-13. Due to the level of assistance needed from the Police to access records it was agreed that only 50 of the 138 cannabis farms, detected and recorded during this period, would be analysed. A random number generator was used to select 50 cases. Content analysis was then used to extract the data across 14 specific variables, including: type of premises, personal characteristics, and previous convictions relating to the suspects. The benefit of quantitative approaches allows straightforward collation and analysis of information and trends (O’Leary, 2004). Whilst it may be less affected by researcher bias (O’Leary, 2004), police data does not capture all crime and can reflect the extent of police effectiveness in detecting a particular phenomena (Jupp, 1989); albeit there is nothing to suggest the police are more adept at detecting one type of cannabis cultivation from another.

Whilst quantitative approaches show what is happening, qualitative approaches are more effective in answering why it is happening by focusing on the individual's subjective view of the world and providing meaning (Sarantakos, 2005). As such the study was supplemented with questionnaire data, using a variety of 16 open and closed questions, some of which were supplemented with a Likert scale. This was an opportunity sample distributed to staff from the Police Station where the study was conducted. Twenty-two respondents returned the questionnaire, comprising 17 male and 5 female officers, the majority of these were Constables (14), supplemented by 6 Inspectors and 2 Sergeants. These were an operationally experienced group with the majority (82\%) stating they had over 10 years police service. Appropriate ethical procedures were followed, with all respondents remaining anonymous and providing informed consent (Punch, 1986). The use of a mixed questionnaire provided flexibility and as Maxfield (2005) suggests, can create a more interesting questionnaire for respondents to complete. Nonetheless limitations in the use of questionnaires exist, notably: 
variability in the veracity of respondents; lack of clarification for the respondents; and distortion through memory or bias (Mason, 2006; Maxfield, 2005). A copy of the questions can be found in the Appendix.

\section{FINDINGS}

QUANTITATIVE - WHAT POLICE AND LOCAL GOVERNMENT RECORDS TELL US

Police records found that the discovered cannabis cultivations ranged in size between 5 and 562 plants, and could be categorised, and further analysed, across three specific types of premises: social residential (managed by social housing trusts), private residential, and commercial premises.

\section{TABLE 1 HERE}

Table 1 demonstrates that the vast majority of cannabis farms were discovered in residential premises (divided between social and private housing), with much fewer farms found in commercial premises, such as warehouses. Although the average number of plants found was 51, there was a significant difference in the average number of plants discovered in each type of premises, with more detected within private residential (69) than social housing (19). Further, business premises, although fewer in number, overshadow both with an average of 137 plants recovered. Analysis showed that $82 \%$ of the growers were cultivating over 10 plants, perceived by the UK government as above the level associated with personal use.

Table 2 (below) shows the diverse methods by which the cannabis farms were identified. The majority are discovered through the execution of a search warrant by the police, which implies some previous knowledge of a farm being present. Conversely, there also appears some level of reactive or 
incidental discovery, with general police activities such as routine patrol, assisting bailiffs or the television licensing authorities, and executing a ‘dangerous dog' warrant also reported.

TABLE 2 HERE

\section{POLICE RECORDS - SUSPECT AND OFFENDER CHARACTERISTICS}

The study then analysed the characteristics of the 61 suspects associated with the detected cannabis farms, who were either prosecuted or otherwise sanctioned (i.e. police caution). 53 were male, and 8 female, with an age range between 20 and 70 years (mean 36 years). The vast majority of these were British, with 47 (77\%) classified as White-British, 10 non-white British (16\%), and four (6\%) foreign nationals (comprising Vietnamese (2), Portuguese (1), Chinese (1)). Although these overseas nationalities were few in number they were associated with significantly larger seizures, as from the three farms they were involved with a total of 762 cannabis plants were found (mean 254). This can be compared to the 47 cannabis farms linked to British nationals, from which 1786 plants were seized (mean 38).

The next stage was to assess the previous criminal convictions of those involved. As antecedent information was missing for the foreign nationals, details were only available for 57 of the suspects. The sample shared 344 prior convictions (mean 6 prior convictions). Whilst numbers of prior convictions ranged from 0-38, 20 (35\%) had no prior criminal history, whilst 14 (24.6\%) had more than ten prior convictions. Further, nine (15.8\%) had between 1-4 convictions and 14 (24.6\%) between 5-9 convictions. 59.5\% of offenders showed an offence of theft or assault in their background, with 54.5\% having a previous drug conviction. The most common first conviction was theft and this was exhibited by $29.7 \%$ of offenders. 
TABLE 3 HERE

\section{QUESTIONNAIRE - POLICE OFFICER OPINION}

The second stage of the study was to examine practitioner opinion in the area the cannabis farms were discovered. Twenty-two operational officers from the area completed the questionnaires - the majority of whom stated they had previously dealt with cannabis farms (one reported dealing with over 50). Twenty-one (95\%) reported a dramatic increase in the prevalence of cannabis farms. All recognised the operational burden this was creating, with six (27\%) referring to this as a large burden, and 12 (55\%) as a reasonable burden. This finding is particularly interesting when exploring Police views as to the prioritisation of cannabis and cannabis farms, illustrated below.

\section{TABLE 4 HERE}

As can be seen, although officers saw the phenomenon as a significant burden on the Police, there was some apathy relating to its prioritisation. Only three (14\%) viewed cannabis as a high level priority. When further asked how cannabis farms (that is the location where the drug was cultivated), should be treated, similar opinions prevailed with only five (23\%) viewing them as a high priority. It appears the majority of respondents viewed cannabis, and its production, as a medium to low-level priority.

A more open style of question asked officers how they thought the community viewed cannabis farms. Content analysis of these free text replies saw a variety of views. The most common response was that the community were worried for their safety, because cannabis farmers had, "little or no concern for people living nearby”. Respondents argued this viewpoint and a fear of retaliation led some individuals to withhold information from the Police. However, others had a different view to explain the lack of information passed by the public relating to cannabis farms. Some respondents argued that cannabis and its cultivation have become the norm, with many residents feeling it should be legalised. This diversity of response was explained in the following quote, "The view of the local 
residents depends on the area. Where there is less cannabis usage then the residents are appalled and find it offensive that it occurs near them. In other areas the local residents are burgling the houses to gain the crop and save time for themselves” (source: Police Constable). One respondent also suggested that only those who have been directly affected would be concerned (for example, landlords whose rented accommodation had been damaged), with impact unlikely to spread to the wider community.

Only two respondents (9\%) felt that cannabis farms could be prevented. One officer wrote, "Legalise possession of cannabis and make it available cheaply enough so as to make it unprofitable for OCGs [organized crime groups] and provide punitive punishment (severe minimum sentence) for those who break the law and continue to grow and supply cannabis” (source: Inspector). The majority were more pessimistic. They replicated the debate outlined in the literature review, arguing that the current environment provided a unique opportunity for the promulgation of domestic cannabis cultivation, citing: the high demand for cannabis; the high yield and significant profit in a relatively short period of time; easy access to equipment and information; little deterrence due to the invisibility of indoor growing; and diminishing police resources. Police Officers highlighted that by the time one cannabis farm is closed many others are set up.

The respondents were also presented with the typology outlined by Hough et al. (2003), and asked which category of individual they were most likely to observe in their operational duties. Although one officer felt the most common grower was motivated by sole use, respondents felt cultivation was most likely conducted by commercial growers ( $\mathrm{n}=16,73 \%)$, or social /commercial grower $(\mathrm{n}=4$, 18\%). One respondent believed there was a category missing, explaining the majority of individuals now grew cannabis on behalf of organised crime groups, either voluntarily or through coercion. This led to a wider issue in relation to the association of organized crime with cannabis farms, which was also explored in the questionnaire. All respondents believed that there was some level of involvement by organized crime on cannabis farms. Some respondents believed that organized crime groups (OCGs) prey on innocent people with no previous convictions, in this way intimidating individuals to 
shelter and maintain cannabis plants on their behalf. As one respondent said, "I now believe that - to avoid the huge potential loss of revenue if we find a large cannabis farm - organised crime groups are now using multiple addresses of loose associates, vulnerable people and customers, so that potential losses are more manageable if we close down one particular farm. Many of these growers are coerced into growing for the OCGs”. This point, made by a Neighbourhood Inspector, is reiterated by a Constable who wrote, "It is also apparent that there are certain gangs using bullying techniques on single parents and people in their community to ensure they have a crop of cannabis plants in their house, thereby any detection will be on the person with the crop and not the original source. They are then selling the cannabis for their own profit”. A Police Sergeant also argued that organized crime must play a key part, due to the sheer scale of the cannabis operation, which can demand large sums of money to initiate.

\section{DISCUSSION}

This study has examined the pattern of domestic cannabis cultivation by providing a snapshot of cannabis farms discovered by police officers working in a UK urban environment over a two-year period. Although caution should be taken when generalising information obtained from a small sample in a specific area, the information reflects many of the previous trends and provides further detail in relation to the types and prevalence of the people and premises involved.

One of the first points to be made is that the study supports the significant body of evidence that argues the domestic cultivation of cannabis is increasing dramatically across the UK and internationally. In this study 138 cannabis farms were detected in a relatively small area (41 square miles), over a two-year period. It appears the discovery of cannabis farms is a constant feature of contemporary policing, with 95\% of those practitioners surveyed saying this increase had been dramatic. 
Secondly the question of who is most likely to grow cannabis, and where they are likely to grow it, appears to be a constantly changing picture. In the UK indoor domestic cultivation is no longer predominated by large scale growers, such as South East Asian organised crime groups, who engage on a large scale (Kirby \& Penna, 2010). Although these farms can still be found the frequency and range of findings suggest there is an increasing normalisation of cannabis cultivation in the UK as more and more British individuals are willing to grow cannabis where they (and possibly their children), live. Cultivations in dwellings far outweigh those found in commercial premises, with the number of plants grown varying significantly between personal use (5 plants) and commercial profit (562).

This leads the discussion to examine the motivation behind those who cultivate the plant. Sole and social growers are widely featured in previous literature. Generally they cultivate cannabis to improve the quality of the product, to avoid 'real' drug dealers, and for the pleasure of growing it themselves (Weishet, 1992; Hough et al., 2003). This study showed that $82 \%$ of the premises had more cannabis than was needed for personal use, providing an increasing level of confidence that a high proportion of growers do make some profit from their labours. Indeed 91\% of the police officers surveyed were of the opinion there was some commercial intent associated with the majority of crops they discovered. As such an increasing number of growers appear to obtain some financial profit although it is difficult, based on this information, to differentiate whether these individuals are commercial or social/ commercial growers. Weisheit (1992) for example used the typology of 'Pragmatists' to describe those who cultivate cannabis to earn money in desperate times, whilst others have seen cannabis cultivation as preferable to a 'regular' job (Hough et al., 2003). Further research may reveal the subtleties of this phenomena.

Further insight is obtained when looking at the characteristics of those who grow cannabis. Very little research has previously been done in this area and the findings demonstrate a significant diversity across the individuals involved. There were a significant number of individuals for whom cannabis cultivation was just one further incident in a career of serious and often violent offences, which also 
included prior drug offending. Whilst persistent offenders were apparent there were also a large proportion (35\%) of suspects who had no prior conviction. Previous research indicates that (generally speaking) the peak age of offending occurs between mid to late adolescence (Gottfredson and Hirschi, 1990). The fact that offenders found within this study had an average age of 37.5 years suggests many individuals, previously of good character, could potentially be criminalized by this activity. In essence this creates policy difficulties for the Criminal Justice System who when faced with the single problem of domestic cannabis cultivation are confronted by a diversity of offenders, ranging from serious and violent persistent offenders to late onset first time offenders.

Ominously there also remains a clear link to organized crime. It has been suggested that organized crime groups are associated with the cultivation of cannabis due to its high profit and low risk status (ACPO, 2012), and this view was overwhelmingly endorsed by the respondents. They agreed with ACPO (2012) that multiple farms are used to dilute the risk of detection, and that some individuals are forced to grow cannabis on behalf of others to offset debt (debt bondage). From the responses provided, police officers feel a significant number of vulnerable individuals, who reside in areas of low income and who have a weak relationship with the Police and other agencies are being coerced into growing cannabis for organized crime groups. Although no conclusive independent evidence supported this assertion, this opinion could explain further why such a high number of cannabis farms are being found in residential housing, and why such large seizures are made. Clearly further research is required, although it is argued a 'coerced grower' category (defined as a vulnerable individual who is pressured, forced, bullied or intimidated into growing cannabis for the benefit of an organized crime group or member), should be introduced to assist this analysis.

In the UK the study shows the domestic cultivation of cannabis creates significant problems for the CJS. Turning specifically to the Police it is also clear that this phenomenon creates particular problems to an organisation that is facing a reduced budget. To operate efficiently the police are reliant on the support of the community, although much of the evidence points to the Police receiving little assistance from this avenue. Interestingly although the study found some practitioner apathy to 
the prioritisation of cannabis farms, $48 \%$ of discoveries were based upon police intelligence. Overall, police officers were generally pessimistic about the future. Nearly all police respondents were of the opinion cannabis farms could not be prevented, for the reasons articulated in the literature review. The two respondents who thought prevention was possible supported Potter (2010) by suggesting other methods to target users, landlords and grow shops, rather than just the farms. Clearly the increased proliferation of domestic cannabis cultivation, together with the questionable impact of current policy, will maintain this phenomenon as a difficult issue to be resolved. Recent policy decisions in Uruguay and certain US states (Travis, 2014), will intensify the debate to legalise or decriminalise specific use of cannabis and counteract the increasingly negative effects it has on public resources.

\section{CONCLUSION}

This small study indicates that the profile of domestic cannabis cultivation is changing across the UK. Situational changes, such as technology and the promulgation of knowledge, has allowed cultivation to evolve from outside to indoors. Whilst previous commentators have reported that growers use residential housing this study has found the volume of growers, living in residential housing, has been increasing whilst those cultivations within larger commercial premises appears to be reducing. Further the data also indicates that OCGs are also using residential housing. These smaller, yet more prolific cannabis farms are therefore placing a greater burden on the Police and have potential to increase the strain on prisons.

Analysis shows a diverse range of suspects from 'late onset first time offenders' to 'serious and persistent offenders'. As such the study can serve to endorse a variety of motivations within the growers. However as $82 \%$ grew more than was needed for personal use, this supported the police view that some degree of financial element was present, whether this was to subsidise wages or welfare benefit, or generate more significant commercial profit. 
The discovery of a small number of farms in commercially rented premises, together with the involvement of four foreign nationals generated some limited evidence as to the involvement of organised crime. However, there was a constant reference to this association by practitioners who felt the link was greater. Specifically, they felt organized crime groups were involved in coercing vulnerable individuals into growing cannabis. Further it was feared the community perceived cannabis farms as intimidating and served to stifle communication between the Police and residents. Whilst these views were persuasive there was limited evidence to support them and they require further exploration.

Finally, findings from the questionnaire suggested that cannabis farms are having a significant impact on police resources, but reducing their growth has appeared impossible. Offenders are operating in an environment that presents increasing opportunity to make money. As such although tactical interventions make small levels of impact they ultimately fail to reduce the phenomenon. As policy continues to move between legalisation (or decriminalisation), and prohibition (Hall, 2009), further research is needed to inform the feasibility of these approaches, specifically whether: punitive punishments prevent future cultivation offences; punishing first time offenders deters or provokes further offending; and whether the proliferation of specialist information and equipment can actually be eradicated. Perhaps, as cannabis increasingly gains legal status across the world, political pressure for its legalisation in the UK is likely to build in Europe, particularly due to its potential for tax revenue rather than its current tax burden. 


\section{REFERENCES}

ACPO (2010) Findings from the UK National Problem Profile. Commercial Cultivation of Cannabis.

“Three years on...”. http://www.acpo.police.uk/documents/crime/2010/201008CRICCC01.pdf .

[Published: 07.2010] [Last Accessed: 23.04.2014].

ACPO (2012) UK National Problem Profile- Commercial Cultivation of Cannabis 2012.

Ashton, C. (2001) Pharmacology and effects of cannabis: a brief review. British Journal of Psychiatry, Vol 178, pp. 101-106.

Akgul, A., \& Sever, M. (2014) Combatting illegal cannabis cultivation in Turkey, Trends in Organised Crime, Vol. 17, pp 220-223.

Bouchard, M. (2007). A capture-recapture model to estimate the size of criminal populations and the risks of detection in a marijuana cultivation industry. Journal of Quantitative Criminology, Vol 23, pp. 221-241. 
Bouchard, M., Alain, M., and Nguyen, H. (2009). Convenient labour: The prevalence and nature of youth involvement in the cannabis cultivation industry. International Journal of Drug Policy, Vol. 20, pp. $467-474$.

Bovenkerk, F., and Hogewind, W. I. M. (2002). Hemp cultivation in the Netherlands: The problem of criminality and law enforcement Hennepteelt in Nederland: het problem van de criminaliteit en haar bestrijding. Utrecht: Willem Pompe Instituut voor Strafwetenschappen.

Collison, M. (1995) Police, drugs and community. London: Free Association Books.

CJP (2006) Operation Keymer- Nipping Cannabis Cultivation in the Bud.

http://www.cjp.org.uk/news/archive/operation-keymer-nipping-cannabis-cultivation-in-the-bud-25-

09-2006/ .[Published: 25.09.2006] [Last Accessed: 23.04.2014].

Daly, M. (2007) Plant warfare. Druglink, Vol 22(2), pp. 6-9.

Decorte, T. (2010) The case for small-scale domestic cannabis cultivation. International Journal of Drug Policy, Vol. 21, pp. 271-275.

Decorte, T., Potter, G.R., and Bouchard, M. (2011) World Wide Weed: Global Trends in Cannabis Cultivation and its Control. Ashgate: Surrey.

Ekblom, P. (2003) Organised Crime and the conjunction of criminal opportunity framework, in Edwards, A. \& Gill, P. (eds), Transnational Organised Crime: Perspectives on global security, London: Routledge.

Felson, M. (2002) (3rd Ed), Crime and Everyday Life. London: Sage.

Fountain, J., and Korf, D.J. (Eds.) (2007) Drugs in society: European perspectives. Oxford/New York: Radcliffe Publishing.

Gettman, J. (2006). Marijuana production in the United States. The Bulletin of Cannabis Reform. http://www.drugscience.org/Archive/bcr2/intro.html. [Last Accessed: 23.04.2014].

Ghodse, H. (2002) (3rd Ed). Drugs and Addictive Behaviour: A Guide to Treatment. Cambridge: Cambridge University Press.

Gottfredson, M., and Hirschi, T. (1990) A General Theory of Crime. Stanford: Stanford University Press. 
Hall, W. (2009) The adverse health effects of cannabis use: What are they and what are their implications for policy? International Journal of Drug Policy, 20(6), 458-466.

Hough, M., Warburton, H., Few, B., May, T., Man, L.H., Witton, J., and Turnbull, P.J. (2003) A Growing Market: The domestic cultivation of cannabis. York: Joseph Rowntree Foundation. IDMU (2011) Cannabis Use in Britain. http://www.idmu.co.uk/cannabis-use-in-britain.htm . [Last Accessed: 14.11.2013].

IDMU (2013) Cannabis Plants- Cultivation and Yields. http://www.idmu.co.uk/cannabis-plantscultivation-yields.htm .[Last Accessed: 14.11.2013].

Jansen, A.C.M. (2002). 'The economics of cannabis-cultivation in Europe’ Paper presented at the 2nd European Conference on Drug Trafficking and Law Enforcement. Paris. http://www.cedrouva.org/lib/jansen.economics.html. [Last Accessed: 23.04.2014].

Jenkins, R. (2006) Cannabis and Young People: Reviewing the Evidence. London: Jessica Kingsley Publishers.

Jupp, V. (1989) Methods of Criminological Research. London: Routledge.

Kennedy, D.M.(2008) Detterence and Crime Prevention: Reconsidering the prospect of sanction, London: Routledge.

Kirby, S. (2013) Effective Policing: Implementation in theory and practice, Basingstoke: Palgrave MacMillan

Kirby, S. \& Penna, S. (2010) Policing mobile criminality: Towards a situational crime prevention approach to Organised Crime, in Bullock, K. Clarke, R.V. \& Tilley, N. (eds) Situational prevention of Organised Crime, Cullompton: Willan.

Mason, J. (2006) Mixing methods in a qualitatively driven way. Qualitative Research, Vol 6 (1), pp. 9-25.

Maxfield, M.G. (2005) Survey Research and Other Ways of Asking Quetions in Maxfield, M.G., and Babbie, E.R. (2011) (6th Ed). Research Methods for Criminal Justice and Criminology. Belmont, CA: Wadsworth Publishing.

May, T., Warburton, H., Turnbull, P. and Hough, M. (2002) Times they are a-changing: Policing of cannabis. York: Joseph Rowntree Foundation. 
Mills, J.H. (2003) Cannabis Britannica: Emprice, Trade, and Prohibition 1800-1928. New York: Oxford University Press.

National Crime Agency (2014), National Strategic Assessment of Serious and Organised Crime 2014, Crown: NCA.

O’Brien, R. (2013) Ofgem cracks down as cannabis farms steal electricity. http://uk.reuters.com/article/2013/07/03/uk-ofgem-cannabis-idUKBRE96208O20130703. [Published: 03.07.2013] [Last Accessed: 23.04.2014].

O’Leary, Z. (2004) The Essential Guide to Doing Research. London: Sage.

Potter, G.R. (2008). The growth of cannabis cultivation: explanations for import substitution in the UK. In D. J. Korf (Ed.), Cannabis in Europe: Dynamics in perception, policy and markets (pp. 87105). Lengerich, Pabst Science Publishers.

Potter, G.R. (2010) Weed, need and greed: A study of domestic cannabis cultivation, London: Free Association Press.

Potter, G.R., Bouchard, M., and Decorte, T. (2011) The Globalization of Cannabis Cultivation, in Decorte, T., Potter, G.R., and Bouchard, M. (eds), World Wide Weed: Global Trends in Cannabis Cultivation and its Control. Surrey: Ashgate.

Punch, M. (1986) The Politics and Ethics of Fieldwork. London: Sage.

Sarantakos, S. (2005) (3rd Ed) Social Research. Hampshire: Palgrave Macmillian.

Shapiro, H. (2012) Weeding out the dope. Druglink, May/June.

http://www.drugscope.org.uk/Resources/Drugscope/Documents/PDF/Publications/weedingoutthedope .pdf. [Last Accessed: 23.04.2012].

Silverstone, D. (2011) World wide weed: global trends in cannabis cultivation and its control - a book review, Global Crime, 13(1), pp67-69.

Shute, J. (2013) Cannabis farms: a growing blight on village life http://www.telegraph.co.uk/earth/countryside/10223399/Cannabis-farms-a-growing-blight-on-villagelife.html [Published: 05.08.2013] [Last Accessed: 07.11.2013].

Spapens, T., van de Bunt, H. \& Rastovac, L. (2007) The world behind cannabis cultivation De wereid achter de wietteelt, Den Haag: Boom Juridische Uitgevers. 
Travis, A. (2014) UN: cannabis law changes pose 'very grave danger to public health': International Narcotics Control Board calls US and Uruguay moves on cannabis 'misguided initiatives'.

http://www.theguardian.com/society/2014/mar/04/un-warning-cannabis-law-change-us-uruguay.

[Published: 04.03.2014] [Last Accessed: 23.05.2014].

Van Hove, W., Van Damme, P., Meert, N. (xx) Factors determining yield and quality of illicit indoor cannabis (Cannabis spp) production. Forensic Science International, 212 (1-3), 15-5-163.

Weisheit, R.A. (1991). The intangible rewards from crime: The case of domestic marijuana cultivation. Crime and Delinquency, Vol 37(4), pp. 506-527.

Weisheit, R.A. (1992). Domestic marijuana. A neglected industry. New York: Greenwood Press.

Wilkins, C., Bhatta, K., \& Casswell, S. (2002) The effectiveness of cannabis crop eradication operations in New Zealand, Drug \& Alcohol Review, 21(4), pp369-374.

Woodman, C. (2013) How to spot if you have a cannabis farm next door http://www.theguardian.com/society/shortcuts/2013/oct/15/spot-if-cannabis-farm-next-door. [Published: 15.10.2013] [Last Accessed: 13.11.2013].

Wouters, M., Korf, D.J. \& Kroeske, B. (2007) Tough policy, hot summer. A study of dismantling of hemp plantations in the Netherlands, Amsterdam: Rozenberg Publishers.

Wouters, M. (2008) Controlling cannabis cultivation in the Netherlands, in D.J. Korf (ed.) Cannabis in Europe: Dynamics in perception, policy and markets, Lengerich: Pabst Science Publishers. 


\section{TABLES}

Table 1: Detected Cannabis Farms, categorised in relation to premise type. Personal/excessive/commercial categories based on ACPO (2012) policy guidance.

\begin{tabular}{|l|l|l|l|l|}
\hline & $\begin{array}{l}\text { Social (rented) } \\
\text { residential }\end{array}$ & $\begin{array}{l}\text { Private } \\
\text { residential }\end{array}$ & $\begin{array}{l}\text { Commercial } \\
\text { premises }\end{array}$ & Total \\
\hline Number of cannabis farms & 22 & 25 & 3 & 50 \\
\hline Number of plants found & 418 & 1719 & 411 & 2548 \\
\hline Range of plant numbers & $5-60$ & $6-562$ & $10-330$ & 137 \\
\hline $\begin{array}{l}\text { Mean number of plants found } \\
\text { in each premises }\end{array}$ & 19 & 69 & 0 & $9(18 \%)$ \\
\hline $\begin{array}{l}\text { Number of premises with <10 } \\
\text { plants (personal use) }\end{array}$ & $6(27.3 \%)$ & $3(12 \%)$ & $1(33.3 \%)$ & $23(46 \%)$ \\
\hline $\begin{array}{l}\text { Number of premises with 10-24 } \\
\text { plants (excessive) }\end{array}$ & $9(40.9 \%)$ & $13(52 \%)$ & $2(66.7 \%)$ & $18(36 \%)$ \\
\hline $\begin{array}{l}\text { Number of premises with } 25+ \\
\text { plants (commercial) }\end{array}$ & $7(31.82 \%)$ & $9(36 \%)$ & & \\
\hline
\end{tabular}


Table 2 (below) Method of detection in relation to each Cannabis Farm

\begin{tabular}{|l|l|}
\hline Discovered by fire service & $2(4 \%)$ \\
\hline Discovered on routine police patrol & $2(4 \%)$ \\
\hline Discovered/suspected/reported by member public & $4(8 \%)$ \\
\hline Discovered after report of burglary & $5(10 \%)$ \\
\hline Discovered during other associated police activity & $9(18 \%)$ \\
\hline Police intelligence leading to search warrant & $24(48 \%)$ \\
\hline Reason unrecorded & $4(8 \%)$ \\
\hline
\end{tabular}

Table 3: Prior convictions of cannabis growers

\begin{tabular}{|l|l|l|}
\hline & $\begin{array}{l}\text { Number of offenders displaying } \\
\text { this type of offence as first } \\
\text { conviction }\end{array}$ & $\begin{array}{l}\text { Number of offenders displaying } \\
\text { this type of offence conviction }\end{array}$ \\
\hline Theft & $11(29.7 \%)$ & $22(59.5 \%)$ \\
\hline Burglary & $3(8.1 \%)$ & $9(24.3 \%)$ \\
\hline Handling stolen goods & $2(5.4 \%)$ & $6(16.2 \%)$ \\
\hline Fraud & $1(2.7 \%)$ & $8(21.6 \%)$ \\
\hline Assault & $4(10.8 \%)$ & $22(59.5 \%)$ \\
\hline Firearms & $2(5.4 \%)$ & $3(8.1 \%)$ \\
\hline Public Disorder & 0 & $9(24.3 \%)$ \\
\hline Weapons & $4(10.8 \%)$ & $7(18.9 \%)$ \\
\hline Robbery & $1(2.7 \%)$ & $3(8.1 \%)$ \\
\hline Damage & $5(13.5 \%)$ & $14(37.8 \%)$ \\
\hline Driving (eg drink driving) & $3(8.1 \%)$ & $12(32.4 \%)$ \\
\hline Drugs & $1(2.7 \%)$ & $20(54.5 \%)$ \\
\hline
\end{tabular}


Table 4: showing police officer views as to cannabis and cannabis farms as a priority for the police.

\begin{tabular}{|l|l|l|}
\hline & $\begin{array}{l}\text { Where do you see cannabis as a } \\
\text { priority for the police? }\end{array}$ & $\begin{array}{l}\text { Where do you see cannabis farms } \\
\text { as a priority for the police? }\end{array}$ \\
\hline Not a priority & $1(4 \%)$ & 0 \\
\hline Low priority & $4(18 \%)$ & $3(14 \%)$ \\
\hline Medium level priority & $14(64 \%)$ & $14(64 \%)$ \\
\hline High level priority & $3(14 \%)$ & $5(23 \%)$ \\
\hline
\end{tabular}

\section{Appendix}

A summary of the questions provided to operational police officers

1. Are you: Male or Female

2. What age bracket do you fall into: $18-24 ; 25-34 ; 35-44 ; 45-54 ; 55+$

3. What is your role in the police force?

4. Please state your length of service: $<2$ years; $2-5$ years; $5-10$ years; $10-20$ years; $>20$ years

5. Where do you see cannabis as a priority for police?: Not a priority; Low priority; Neither high nor low; Medium priority; High priority

6. Where do you see cannabis farms as a priority for police? Not a priority; Low priority; Neither high nor low or Medium priority; High priority

7. In your opinion, what category do the majority of cannabis farm offenders fall under? (circle only one)

a) The sole-use grower- cultivating cannabis for their personal use and use with friends

b) The medical grower- use for them and others purely for medical reasons

c) The social grower- cultivation to ensure good quality and good value cannabis for themselves and friends 
d) The social/commercial grower-growing for themselves and friends but with an element of profit

e) The commercial grower- growing to make money, with anyone as a possible customer

8. Do you believe there has been an increasing trend in the prevalence of cannabis farms in the past 20 years?: No- a large decrease; No- a slight decrease; A stability in cannabis farms; Yes- a slight increase; Yes- a dramatic increase

9. What are some of the community views about cannabis farms that you have been made aware of?

10. How much of a burden, in relation to time, money and resources, are cannabis farms to the police force in comparison to other offences?: Not a burden; A small burden; No different to the majority of crimes; A reasonable burden; A very large burden

11. Do you know what the force policy is if you come across a cannabis farm? Please detail.

12. Have you ever dealt with a cannabis farm yourself? Please explain a particular situation of your choice, if so.

13. In your opinion, do you think cannabis farms can be prevented?: YES / NO

14. If YES, how? If NO, why?

15. If any, what is the impact of organized crime on cannabis farms?

16. How do you think cannabis farms are best dealt with? 